\title{
PERCEPÇÕES SOBRE A EDUCAÇ̃̃O EM ANATOMIA HUMANA PÓS-PANDEMIA DO COVID-19: REVISÃO SISTEMÁTICA DA LITERATURA
}

\author{
Perceptions about Human Anatomy Education Post-COVID-19 Pandemic: Systematic \\ Literature Review
}

Caroline Fernandes dos Santos Bottino ${ }^{1}$

\begin{abstract}
Resumo: No ano de 2020, a pandemia do novo coronavírus impeliu ao isolamento social e à virtualização da educação. Nesse cenário, o objetivo deste estudo foi realizar uma revisão sistemática da literatura para investigar como os docentes utilizaram as tecnologias digitais de informação e comunicação (TDIC) no ensino remoto de anatomia humana, assim como suas percepções e perspectivas sobre a educação em anatomia pós-pandemia. Entre os 214 artigos encontrados, cinco foram analisados mediante os critérios de inclusão. Como resultados, os professores realizaram aulas teóricas e práticas, síncronas e assíncronas, por videoconferências com interação, assim como disponibilizaram recursos educacionais (RE) tais como fotos, vídeos, atlas virtuais $2 \mathrm{D}$ e $3 \mathrm{D}$, simulações virtuais e programas de dissecção on-line, em ambientes virtuais de aprendizagem. Entre as percepções, foi relatado: possibilidade de criar RE, necessidade de melhorar habilidades no uso de TDIC, dificuldade em avaliar, dificuldades na relação professor-aluno, falta de tempo e sobrecarga de trabalho. As perspectivas sobre a educação em anatomia pós-pandemia incluíram uma abertura à inserção de TDIC e ao ensino híbrido, uma reavaliação da necessidade do uso de cadáveres, a colaboração docente em comunidades de práticas e um maior suporte institucional à educação on-line. Como conclusão, é difícil prever o impacto do ensino remoto na educação em anatomia; contudo, os estudos analisados apontam para uma mudança de paradigmas por meio da inserção de TDIC no currículo e da reavaliação do uso de cadáveres em aulas práticas.
\end{abstract}

Palavras-chave: Ensino de Anatomia. Ensino remoto. Tecnologias digitais. Coronavírus. Tecnologias Digitais de Informação e Comunicação.

Abstract: In 2020, the new coronavirus pandemic drove social isolation and the virtualization of education. In this scenario, the objective was to conduct a systematic literature review to investigate how professors used digital information and communication technologies (DICT) for remote teaching in human anatomy and their perceptions and perspectives about anatomy education post-pandemic. Among the 214 articles found, five were analyzed according to inclusion criteria. The results show that professors delivered lectures and laboratory sessions, either synchronous or asynchronous, by interactive video conferences and provided ER (educational resources) such as photos, videos, 2D and 3D virtual atlases, virtual simulations,

\footnotetext{
${ }^{1}$ Professora de Neurociências e Neurobiologia do Instituto de Saúde de Nova Friburgo (ISNF) da Universidade Federal Fluminense (UFF). Licenciada e Bacharel em Ciências Biológicas pela Universidade do Estado do Rio de Janeiro (UERJ). Mestre em Morfologia pela UERJ. Doutora em Biologia Humana e Experimental pela UERJ. Especialista em A Moderna Educação: Metodologias, Tendências e Foco no Aluno pela Pontifícia Universidade Católica do Rio Grande do Sul (PUCRS). ORCID: http://orcid.org/0000-0002-2420-3836. E-mail: cf_santos@id.uff.br.
} 
and online dissection programs in learning management systems. Among perceptions, they reported the opportunity to create educational resources, improve their skills in DICT, difficulties in evaluating and professor-student relationship, little time, and work overload. The perspectives on post-pandemic anatomy education included openness to the insertion of DICT and blended learning, reevaluation of the need for cadavers, professor collaboration in communities of practice, and a meaningful institutional support for online education. In conclusion, it is difficult to predict the impact of remote education on anatomy education. However, the studies point to a paradigm shift by inserting DICT into the curriculum and reevaluating practical classes using cadavers.

Keywords: Anatomy. Remote learning. Digital technologies. Coronavirus. Digital information and communication technologies.

\section{Introdução}

$\mathrm{O}$ conhecimento em anatomia humana é essencial à formação profissional na área da saúde, porque ele possibilita o entendimento sobre as estruturas do corpo humano e o seu funcionamento. O estudo da Anatomia tem como base aulas práticas de observação e dissecção, nas quais o aluno interage manualmente com peças anatômicas e adquire uma percepção tridimensional das estruturas do corpo e de como elas se relacionam. Essa experiência prática favorece o entendimento das patologias e dos problemas clínicos (SINGH et al., 2020).

No Brasil, especialmente em São Paulo, o modelo de ensino e pesquisa em anatomia se pautou em Alfonso Bovero (1871-1937), inspirado pelos ensinamentos adquiridos por ele na Europa (TALAMONI; BERTOLLI FILHO, 2014). O seu modelo de ensino se assemelhou ao empreendido pelos 'reformadores' da anatomia Mondino de Luizzi (1207-1326) e Andreas Vesalius (1514-1564), configurando assim o método tradicional de ensino de anatomia, em que a prioridade é a prática da dissecção e o uso de compêndios e livros-texto (TALAMONI; BERTOLLI FILHO, 2014). Ainda hoje, nota-se uma divergência entre os anatomistas sobre o uso ou não de corpos no ensino da anatomia. McMenamin et al. (2018) enfatizam que eles deveriam ser usados associados a outras múltiplas abordagens de ensino, enquanto Saverino (2020) diz que o estudo da anatomia através da dissecção de corpos tem se tornado cada vez mais raro nas escolas médicas devido à redução das doações e ao crescente número de alunos. Fica evidente a necessidade de busca por alternativas à educação em anatomia pautada no uso estrito de aulas práticas com cadáveres.

$\mathrm{Na}$ educação em anatomia, outros métodos e tecnologias já têm sido muito utilizados, apesar de não serem ainda amplamente difundidos ou acessíveis economicamente para alunos, professores ou instituições de ensino. Como exemplo, pode-se citar a observação de peças dissecadas por terceiros, plastinação, vídeos, recursos on-line (atlas 3D), redes sociais (Facebook, Twitter e YouTube), impressão 3D, realidade aumentada (augmented reality AR) e realidade virtual (virtual reality - VR) (IWANAGA et al., 2021). Uma recente revisão sistemática da literatura investigou o uso de tecnologia na educação em anatomia em artigos publicados no período de 2017 a 2020, encontrando como resultado o uso de smartphones, QR Codes, VR, impressoras 3D e próteses. Como conclusão, a análise revelou um maior interesse dos alunos pelas aulas quando a tecnologia foi associada aos métodos tradicionais de ensino e a maioria dos artigos demonstrou que o desempenho dos alunos foi igual ou melhor nas avaliações comparado às práticas tradicionais (BOFF et al., 2020). 
A COVID-19, doença causada pelo novo coronavírus, foi primeiramente identificada em dezembro de 2019, na cidade de Wuhan, localizada na província de Hubei, na China, e, em 11 de março de 2020, a doença foi considerada uma pandemia pela Organização Mundial da Saúde (OMS, 2020). Diante disso, o distanciamento social imposto pela pandemia forçou as instituições de ensino a adotarem tecnologias digitais de informação e comunicação (TDIC) para que os alunos pudessem continuar a sua rotina de estudos, sendo esta uma nova forma de ensinar rapidamente nomeada ensino remoto (remote learning). Em um primeiro momento, houve uma grande apreensão dos docentes devido à percepção de um ensino de menor qualidade, à falta de tempo para o planejamento pedagógico, à ausência de materiais didáticos e à percepção equivocada de que o ensino remoto seria equivalente à educação a distância (EAD). Segundo Arruda (2020), a EAD traz um estigma de educação inferior ao aprendizado presencial, mas essa afirmação não é correta, sendo refutada em diversos estudos e, recentemente, discutida por Martins (2020).

Segundo Moreira e Schlemmer (2020), o ensino remoto é um modelo temporário de ensino, devido às circunstâncias sanitárias vigentes, que faz uso da tecnologia e do meio digital para que as atividades escolares não sejam interrompidas. No ensino remoto (ou aula remota), o ensino presencial físico é transposto para o meio digital; o processo é centrado no conteúdo e o foco seriam atividades síncronas, em que alunos e professores estão conectados virtualmente ao mesmo tempo (MOREIRA; SCHLEMMER, 2020). Para além de conceituar o ensino remoto, Moreira e Schlemmer (2020) buscaram delimitar conceitualmente a educação mediada pelo digital e pelas suas variantes. Eles perceberam que existem diferentes terminologias para conceitos muito semelhantes, cujo foco pode ser os aspectos tecnológicos ou mais próximos ao potencial pedagógico. Em sua revisão, eles abordaram os conceitos de ensino remoto, ensino à distância, educação à distância, eLearning, educação on-line, web-based learning, open learning, blended learning, educação híbrida e educação digital OnLife (MOREIRA; SCHLEMMER, 2020).

Ao passear por estes conceitos, nota-se uma evolução temporal no uso das TDIC na educação. Sustentada pela internet e pelos ambientes virtuais de aprendizagem (AVA), a EAD promove a construção e a socialização do conhecimento, no qual o aluno é agente da sua aprendizagem, há interatividade síncrona ou assíncrona e o trabalho é colaborativo. A web-based learning (aprendizagem baseada no computador) possibilita que o aluno estude sozinho, informalmente, mediado pela internet. Este também pode construir o seu próprio percurso formativo sem as exigências acadêmicas tradicionais por meio do open learning (aprendizagem aberta). Não obstante, existem conceitos que mesclam a possibilidade de experienciar a educação presencial mediada pela tecnologia juntamente com a EAD, através do blended learning e da educação híbrida (MOREIRA; SCHLEMMER, 2020). Por fim, os autores abordam a educação digital OnLife, que compreende processos de ensino e aprendizagem que não usam a tecnologia como ferramenta, mas sim como um

\begin{abstract}
contínuum de Educação Digital que compreende desde processos de ensino e aprendizagem enriquecidos por $\mathrm{TD}^{2}$ e/ou redes de comunicação, até o desenvolvimento de uma educação totalmente online e digital, tendo variabilidade na frequência e na intensidade tanto de $\mathrm{TD}$, quanto de redes de comunicação (MOREIRA; SCHLEMMER, 2020, p. 24).
\end{abstract}

Segundo Martins (2020), estamos há pelo menos 25 anos tentando inserir a tecnologia na educação escolar no Brasil e, da mesma forma que houve uma naturalização no uso da internet pelos brasileiros, o mesmo acontecerá com a educação mediada pela tecnologia (MARTINS, 2020). Seguindo um pouco a ideia de educação OnLife (mas sem usar este

\footnotetext{
${ }^{2}$ Tecnologias digitais.
} 
termo), Martins (2020) nos diz que, passada a pandemia do novo coronavírus, não fará mais sentido categorizar a educação em presencial ou a distância, uma vez que o uso de TDIC está ressignificando o conceito de distância e de ensino. Para ele, precisamos de uma educação "inteira" para a construção de um futuro melhor para a humanidade.

O ensino remoto demanda o desenvolvimento de competências digitais tanto dos docentes quanto dos alunos e essa discussão já decorre há algum tempo, antes mesmo da pandemia do novo coronavírus. Segundo Silva e Behar (2019), o termo digital competence surgiu em 2006 como uma competência chave para a educação e a formação ao longo da vida, conforme apontado pelo Parlamento Europeu e Comissão Europeia de Cultura e Educação, e possui como definição o "uso seguro e crítico das tecnologias de informação para o trabalho, lazer e para a comunicação" (SILVA; BEHAR, 2019, p. 08). Na educação, o termo começa a ser discutido em 2006, na Noruega, e ganha diferentes definições ao longo dos anos, conforme surgem novas TDIC. Um aspecto em comum entre todos os autores é que a competência digital na educação aborda os elementos "conhecimentos, habilidades e atitudes, meios digitais/tecnológicos e resolução de problemas” (SILVA; BEHAR, 2019, p. 14).

Há dez anos, Santos (2011) discutia a educação no meio virtual considerando aspectos como o novo formato da sala de aula (virtual), as estratégias pedagógicas, os materiais e o papel do professor nesse cenário. Após analisar 13 dissertações desenvolvidas entre 2004 e 2008, ele afirma que a aula virtual é o "cenário de uma experiência didática única, prazerosa, efetiva, eficaz e totalmente condizente com a dinâmica da sociedade da informação". Ainda, uma "comunidade de aprendizagem em rede, de trabalho colaborativo virtual, de horizontalidade da relação educativa, de materiais dinâmicos e de mediação pedagógica fundamentada na interatividade" (SANTOS, 2011, p. 317).

Para Moran (2004, p. 02), "o professor, em qualquer curso presencial, precisa aprender a gerenciar vários espaços e a integrá-los de forma aberta, equilibrada e inovadora". Ao abordar o espaço virtual, por meio do AVA, Moran (2004) enfatiza que o professor precisa adquirir competências para gerir o presencial e o virtual, avaliando o que vale a pena fazer pela internet como complemento ao espaço da sala de aula presencial. Não obstante, as atividades virtuais demandam a atuação em três campos: (1) pesquisa individual do aluno (temas, textos e projetos); (2) comunicação, em que há debate e conversação on-line e off-line; e (3) produção, em que os alunos divulgam os resultados da sua busca em diferentes mídias para a turma e para a comunidade.

Por fim, o conceito de tecnodocência proposto por Lima e Loureiro (2019) se propõe a compreender a docência numa sociedade tecnológica, onde há

integração entre TDIC e Docência com base epistemológica nos modelos interdisciplinares e transdisciplinares, por meio da utilização dos conhecimentos prévios dos docentes e discentes para o desenvolvimento de uma reflexão crítica sobre os processos de ensino, aprendizagem e avaliação (LIMA; LOUREIRO, 2019, p. 98).

Segundo os autores, as TDIC devem ser usadas para a construção do conhecimento e, ao mesmo tempo, devem ser criticadas para que seja possível construir novas tecnologias a partir das vivências e demandas dos próprios professores e alunos (LIMA; LOUREIRO, 2019). A tecnodocência possui dez princípios, os quais enfatizam o professor como aprendiz, a parceria professor-aluno, o conhecimento construído e pautado no conhecimento prévio do aprendiz, integrado de forma interdisciplinar e transdisciplinar, em que o aprendiz desenvolve 


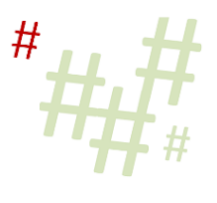

processos, produtos e conhecimento. Ainda, a prática pedagógica deve ser fundamentada em técnicas e metodologias flexíveis, nas quais a docência e as TDIC se integram e se transformam mutuamente (LIMA; LOUREIRO, 2019). Para a Nicolescu (2000), a interdisciplinaridade diz respeito à transferência de métodos de uma disciplina para outra, ultrapassando o limite das disciplinas, enquanto a transdisciplinaridade "diz respeito àquilo que está ao mesmo tempo entre as disciplinas, através das diferentes disciplinas e além de qualquer disciplina" (NICOLESCU, 2000, p. 11).

Ao comentar a educação em anatomia, Evans et al. (2020) ressalta que qualquer movimento de educação on-line requer a integração de plataformas digitais, TDIC e pedagogias que ofereçam oportunidades de aprendizado efetivas e que produzam impacto nos alunos. Reforça, ainda, que a urgência em mover o ensino para o ambiente on-line é uma oportunidade para reavaliar o desenho do currículo de anatomia e o ensino de anatomia, visto que esse novo ambiente oferece uma renovação das abordagens pedagógicas, assim como a sua inovação, que podem oportunizar o aprendizado do aluno (EVANS et al., 2020). Por sua vez, Saverino (2020) evidencia que os anatomistas precisam rever a opinião comum na anatomia, mudando a sua posição de uma disciplina mnemônica ('memorização') e chata, para engajante e fascinante, pelo uso de todas as estratégias ativas, envolventes e tecnológicas disponíveis, colocando o aluno como centro do processo de aprendizagem.

Diante do exposto, o objetivo deste artigo foi realizar uma revisão sistemática da literatura para investigar como os docentes utilizaram as TDIC no ensino remoto de anatomia durante a pandemia do novo coronavírus e a sua visão sobre a educação em anatomia pós-pandemia. As três perguntas de pesquisa foram: (1) Quais ferramentas tecnológicas e estratégias pedagógicas foram utilizadas no ensino remoto de anatomia humana? (2) Quais são as percepções dos professores sobre o ensino remoto e o uso de TDIC? (3) Qual é a percepção dos professores sobre o futuro da educação em anatomia pós-pandemia?

\section{Metodologia}

O presente estudo é uma revisão sistemática da literatura (MOHER et al., 2009) e incluiu artigos originais que avaliaram o ensino de anatomia humana mediado por TDIC no ensino superior durante a pandemia do novo coronavírus. Os estudos já realizados deveriam incluir dados obtidos a partir de entrevistas ou questionários aplicados em professores de anatomia humana. Os estudos foram identificados nas bases de dados PubMed ${ }^{3}$, Biblioteca Virtual em Saúde ${ }^{4}$, SciELO ${ }^{5}$ e DOAJ ${ }^{6}$.

O período de busca compreendeu $1^{\circ}$ de janeiro de 2020 até o presente e a busca foi realizada no dia 5 de janeiro de 2021. Foi utilizado como filtro a Língua Portuguesa ou Inglesa e como descritores os termos MeSH (português/inglês): covid-19/covid-19; coronavírus/coronavirus AND ensino/teaching; aprendizagem/learning; AND anatomia/anatomy; neuroanatomia/neuroanatomy, presentes no título ou no resumo.

Durante a leitura do texto completo dos artigos, as seguintes informações foram coletadas para posterior análise e discussão: (1) ferramentas tecnológicas, estratégias pedagógicas e avaliação; (2) percepção dos docentes sobre as suas competências digitais; (3)

\footnotetext{
${ }^{3}$ Periódicos da área Biomédica e Ciências da Vida (https://pubmed.ncbi.nlm.nih.gov/).

${ }^{4}$ Periódicos da área de Ciências da Saúde (https://bvsalud.org/).

${ }^{5}$ Periódicos científicos brasileiros (https://scielo.org/).

6 Periódicos de acesso aberto das áreas de Ciências, Tecnologia, Medicina, Ciências Sociais, Artes e Humanidades (https://doaj.org/).
} 
percepções sobre o ensino remoto como as facilidades, dificuldades ou oportunidades encontradas; e (4) percepções sobre a educação em anatomia pós-pandemia. Devido ao caráter descritivo do presente estudo, não foi avaliado o risco de viés e a qualidade metodológica de cada estudo.

\section{Resultados e discussão}

\subsection{Estudos analisados}

A busca retornou 214 artigos, sendo 165 duplicados (Figura 1). Após a leitura do título e resumo $(n=49)$, foram excluídos 42 artigos por não se enquadrarem nos critérios de inclusão. Sete artigos foram triados para elegibilidade, pela leitura do texto na íntegra. Após a leitura, dois artigos foram excluídos, porque um avaliou uma metodologia específica e o foco não foi avaliar a educação em anatomia durante a pandemia e o outro avaliou a educação em medicina clínica, sem avaliar a educação em anatomia. Ao final, cinco artigos foram incluídos na análise qualitativa. Não foram encontradas pesquisas realizadas com professores de anatomia em território brasileiro nas bases de dados consultadas para esta pesquisa.

Figura 1 - Fluxo de informação ao longo das diferentes fases da revisão sistemática

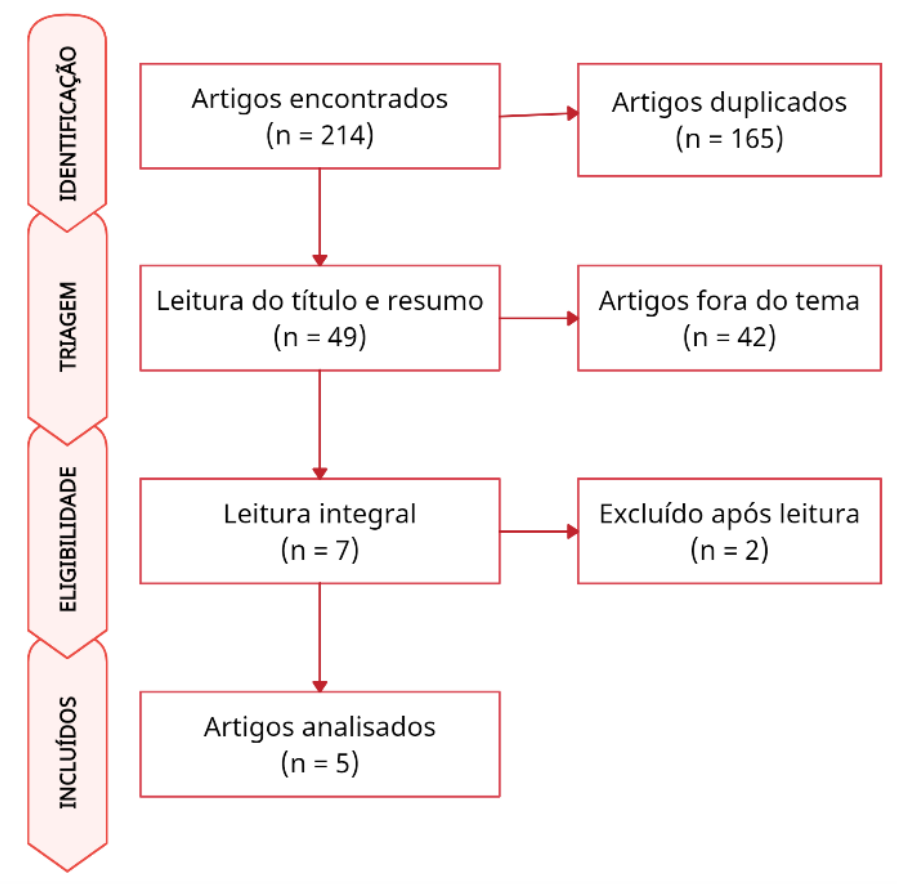

Fonte: Elaborado pela autora (2021).

Uma síntese dos artigos analisados é apresentada na Tabela 1. Todos os estudos tiveram como objetivo principal avaliar as adaptações realizadas na educação em anatomia em um ou mais países, exceto pelo estudo de Wolniczak et al. (2020), cujo objetivo foi relatar as adaptações realizadas por um grupo de professores em sua disciplina e a percepção de professores e alunos. O desenho dos estudos foi observacional, transversal e qualitativo 
(LONGHURST et al., 2020; PATHER et al., 2020), quali-quantitativo (CHENG et al., 2020; HARMON et al., 2021) ou não foi informado (WOLNICZAK et al., 2020). Quando informado, a coleta de dados foi feita no período inicial da pandemia do COVID-19 (primeiro semestre de 2020), por meio de questionário ou perguntas enviadas por sociedades profissionais, lista de e-mails ou redes sociais dos pesquisadores. Os estudos incluíram professores de anatomia de cursos de graduação em medicina ou cursos da área da Saúde, assim como cursos de pós-graduação.

Tabela 1 - Síntese dos artigos analisados. * Estudos originais. ** Possui características de relato de caso. NR, tamanho amostral não relatado

\begin{tabular}{|c|c|c|}
\hline Autoria & Amostra e país & Objetivo e parâmetros analisados \\
\hline $\begin{array}{c}\text { CHENG et al., } \\
2020^{*}\end{array}$ & $\begin{array}{c}\mathrm{n}=77 \text { (estratégias) } \\
\mathrm{n}=359 \text { (percepções) } \\
\text { China, Hong Kong e } \\
\text { Macao }\end{array}$ & $\begin{array}{l}\text { Avaliou as atitudes dos professores de anatomia de escolas } \\
\text { de medicina perante o ensino remoto nas seguintes } \\
\text { dimensões: aulas teóricas, aulas práticas, metodologias } \\
\text { ativas, avaliação e experiência do professor. }\end{array}$ \\
\hline $\begin{array}{c}\text { HARMON et } \\
a l ., 2021^{*}\end{array}$ & $\begin{array}{l}\qquad \mathrm{n}=67 \\
\text { Estados Unidos }(84 \%) \mathrm{e} \\
\text { outros países }(16 \%)\end{array}$ & $\begin{array}{l}\text { Avaliou como os professores de anatomia de graduação e } \\
\text { pós-graduação responderam ao COVID-19. O ensino } \\
\text { realizado pré-pandemia e durante a pandemia foi } \\
\text { comparado considerando aspectos como organização das } \\
\text { aulas teóricas e práticas, organização dos alunos em } \\
\text { grupos, recursos e ferramentas digitais. }\end{array}$ \\
\hline $\begin{array}{l}\text { LONGHURST } \\
\text { et al. } 2020^{*}\end{array}$ & $\begin{array}{c}\mathrm{n}=14 \\
\text { Inglaterra }(86 \%) \mathrm{e} \\
\text { República da Irlanda } \\
(14 \%)\end{array}$ & $\begin{array}{l}\text { Avaliou as abordagens utilizadas no ensino remoto por } \\
\text { professores de anatomia das escolas de medicina. Buscou } \\
\text { entender a variedade de soluções encontradas, sob a ótica } \\
\text { da matriz FOFA (forças, oportunidades, fraquezas e } \\
\text { ameaças) e a percepção dos professores sobre as } \\
\text { mudanças que o ensino remoto trouxe. }\end{array}$ \\
\hline $\begin{array}{l}\text { PATHER et } \\
\text { al., 2020* }\end{array}$ & $\begin{array}{l}\quad \mathrm{n}=18 \\
\text { Austrália e Nova } \\
\text { Zelândia }\end{array}$ & $\begin{array}{l}\text { Buscou documentar e compartilhar as experiências de } \\
\text { professores de anatomia, histologia e/ou embriologia de } \\
\text { graduação e pós-graduação durante o período inicial da } \\
\text { pandemia do COVID-19. }\end{array}$ \\
\hline $\begin{array}{l}\text { WOLNICZAK } \\
\text { et al., 2020** }\end{array}$ & $\begin{array}{c}\mathrm{n}=\mathrm{NR} \\
\text { Alemanha }\end{array}$ & $\begin{array}{c}\text { Sem um objetivo claro, o artigo traz a visão dos alunos e } \\
\text { dos autores (professores) sobre o uso da tecnologia nas } \\
\text { aulas on-line de anatomia. }\end{array}$ \\
\hline
\end{tabular}

Fonte: Elaborado pela autora (2021).

Os resultados apresentados nos estudos tiveram como foco a descrição das TDIC utilizadas nas aulas on-line e as percepções dos professores. Alguns estudos trouxeram recortes de fala dos professores para ilustrar o contexto no qual as TDIC foram utilizadas ou as suas percepções sobre o ensino remoto. Poucos professores e instituições possuíam experiência prévia na oferta de disciplinas on-line, exceto na China (Cheng et al., 2020). As informações coletadas dos estudos foram agrupadas em quatro sessões e resumidas nas Figuras 2 e 3: (1) aulas teóricas e práticas; (2) avaliação da aprendizagem; (3) percepções sobre o ensino remoto; e (4) perspectivas sobre a educação em anatomia pós-pandemia. 
Devido ao caráter majoritariamente qualitativo dos estudos, a presente revisão sistemática não teve como objetivo quantificar os dados relatados, mas sim destacar as evidências mais frequentes e discuti-las à luz da literatura.

\subsection{Aulas teóricas (lectures) e práticas (laboratory)}

As aulas teóricas em anatomia foram realizadas on-line em formato síncrono, assíncrono, ou combinando os dois formatos. A videoconferência foi utilizada nas aulas síncronas e, para interagir com os alunos, foram utilizados os recursos de voz, texto (chat) e aplicativos de enquete ( $p o o l)$ e discussão. O uso de salas de aula simultâneas durante a videoconferência também foi relatado (breakout rooms). As aulas assíncronas foram produzidas a partir da gravação de vídeo com câmera ou pela captura da tela do programa de apresentação de slides. Um artigo mencionou que os alunos poderiam realizar cursos Massive Open Online Courses (MOOC) em anatomia e apresentar, posteriormente, a certificação do cumprimento da carga horária para validação (CHENG et al., 2002).

Antes da pandemia, as universidades realizavam presencialmente aulas práticas com dissecção (dissection), nas quais o aluno punha a 'mão na massa', assim como aulas de observação (prosection), em que o aluno interagia com peças anatômicas previamente dissecadas ou observava o professor realizando a dissecção. Durante a pandemia, alguns professores relataram o cancelamento das aulas práticas, diante da previsão de que seriam ministradas no futuro pós-pandemia (CHENG et al., 2020; PATHER et al., 2020). Cheng et al. (2020) acreditam que isso ocorreu devido ao receio sobre a qualidade da aula prática on-line ou pela perspectiva de que a pandemia não duraria muito tempo. Outros professores relataram a continuidade das aulas práticas em formato híbrido mescladas com aulas práticas presenciais com peças anatômicas e complementadas com o estudo on-line (HARMON et al., 2021; WOLNICZAK et al., 2020). As aulas práticas on-line foram ministradas tanto de forma síncrona quanto assíncrona, por meio de fotos e vídeos de peças anatômicas, atlas virtuais em $2 \mathrm{D}$ e 3D, simulações virtuais e programas de dissecção on-line.

Recursos educacionais (RE) foram criados pelos próprios professores, sendo majoritariamente fotos e vídeos de cadáveres e peças anatômicas. Alguns RE livres também foram buscados na internet, contratados pela instituição de ensino, ou tiveram acesso cedido temporariamente por empresas de educação. Ao relatar a criação de RE, o tema direitos autorais não foi discutido por nenhum estudo. Este tema foi debatido em uma instituição de ensino superior brasileira, uma vez que não havia e-books para o estudo on-line dos alunos. $\mathrm{O}$ professor precisou criar RE, apesar de não entender sobre licenças de uso, o que dificultou a tomada de decisão sobre baixar, copiar e reutilizar os materiais encontrados na internet.

Longhurst et al. (2020) destacam que já existem muitos materiais de boa qualidade, então, deve-se ponderar se vale a pena criar o que já existe, ou seja, 'recriar a roda'. Essa ponderação vai ao encontro com os princípios da educação on-line abordados por Pimentel e Carvalho (2020), os quais apontam que a mudança no papel do professor inclui a curadoria de conteúdo on-line. No processo de curadoria, o professor busca, agrega, organiza e compartilha o que foi encontrado por meio da elaboração de roteiros de estudo (PIMENTEL; CARVALHO, 2020). Longhurst et al. (2020) também relataram uma preocupação dos professores em criar RE que promovessem o engajamento dos alunos e os mantivessem motivados com o seu estudo.

Segundo Cheng et al. (2020), apesar do avanço nos recursos digitais, o estudo da anatomia se fundamenta em modelos, peças anatômicas e cadáveres, assim como demanda 
uma percepção tridimensional da relação entre as estruturas do corpo, o que é difícil alcançar no ensino on-line, no qual o aluno perde a somestesia associada à dissecção e manipulação das peças. Outra questão que surgiu devido à ausência das aulas práticas foi o fato delas estimularem os alunos de medicina a seguirem carreiras em cirurgia, o que pode ter sido comprometido pela pandemia (CHENG et al., 2020). Contudo, cabe ressaltar que vários cursos da área da Saúde possuem anatomia em seu currículo e que, talvez, o impacto da ausência de aulas práticas presenciais com peças anatômicas não seja igual em todos eles.

Os estudos analisados também citaram o uso de métodos ativos de ensino-aprendizagem. No estudo de Pather et al. (2020), alguns professores relataram promover aulas teóricas interativas, aplicando alguns princípios das metodologias ativas, pelo uso de aplicativos de Quiz ou discussão de casos. Entre os métodos ativos relatados por Cheng et al. (2020) estão a aprendizagem baseada em problemas (problem-based learning PBL), aprendizagem baseada em equipes (team-based learning - TBL), sala de aula invertida (flipped classroom) e a discussão em pequenos grupos. Nas aulas síncronas, Harmon et al. (2021) relatam o uso de pequenos grupos para a revisão do conteúdo ou para o estudo de casos, enquanto grupos maiores foram utilizados para a discussão de um determinado tópico da aula prática.

Há quase duas décadas, Moran (2004) apontou que as tecnologias eram utilizadas na universidade e nas escolas para ilustrar o conteúdo e não para criar novos desafios. Nos artigos analisados, nota-se que a urgência em transpor a aula presencial para o ambiente virtual não fugiu a esse aspecto. Os dados apresentados pelos estudos estão em acordo com Moreira e Schlemmer (2020), revelando que, no ensino remoto, houve a transferência e transposição de metodologias e práticas pedagógicas presenciais para o ambiente on-line com o uso, na maioria dos casos, de tecnologias de videoconferência e plataformas digitais sob uma perspectiva instrucional, o que as reduz a instrumento ou ferramenta (MOREIRA; SCHLEMMER, 2020). Exceto pela menção ao uso de metodologias ativas (PATHER et al., 2020), não foram encontradas justificativas pedagógicas que embasassem as escolhas realizadas para a migração do ambiente presencial para o virtual.

\subsection{Avaliação da aprendizagem}

Durante a pandemia, algumas instituições não aplicaram avaliações (CHENG et al., 2020; HARMON et al., 2021; LONGHURST et al., 2020). Quando realizadas, as estratégias utilizadas foram questões objetivas e discursivas, presença on-line do aluno, avaliação subjetiva pelo professor, avaliação por pares, provas com consulta (open-book) e prova prática de observação. Harmon et al. (2021) relataram que a avaliação prática mudou de local, porém, o seu formato não mudou, saindo do contexto do anatômico para ser aplicada via computador. A maioria dos professores continuou aplicando avaliações práticas, nas quais houve uma migração da observação ou dissecção para a análise de imagens. Entre elas, imagens médicas, fotografias de peças anatômicas ou de livros-texto e, em menor grau, modelos virtuais em 3D, vídeos e realidade virtual (HARMON et al., 2021).

Com relação à percepção sobre o aprendizado, a maioria dos respondentes no estudo de Cheng et al. (2020) acharam que os alunos não alcançaram os objetivos de aprendizagem, apesar de $51 \%$ terem relatado estar muito satisfeitos ou satisfeitos com a eficácia da educação on-line. Pather et al. (2020) discutem que será necessário, no período pós-pandemia, avaliar se existiu deficit na aprendizagem de algum conhecimento para posterior correção. 
Uma fala é destacada no estudo de Cheng et al. (2020), em que um professor diz que o AVA facilitou a atribuição e correção de atividades e que ele deveria ser utilizado com maior frequência. Os autores também relataram o aumento no número de avaliações aplicadas de modo on-line, destacando que, para eles, isso refletiu uma maior preocupação dos professores em compreender o progresso dos alunos a cada tópico da aula. Pimentel e Carvalho (2020) reiteram que a avaliação on-line deve ser feita de maneira contínua, numa perspectiva formativa, cujo principal objetivo é que o aluno tenha consciência do seu processo de aprendizagem, em detrimento de saber se será aprovado ou reprovado.

Os estudos de Longhurst et al. (2020) e Pather et al. (2020) identificaram uma preocupação dos professores com o risco de fraude nas avaliações on-line, assim como a dificuldade de fiscalização (PATHER et al., 2020). Pather et al. (2020) comentam que alguns professores modificaram a sua abordagem, realizando avaliação formativa ou pontuações relativas, de forma que a 'cola' se tornasse irrelevante. Outros professores simplesmente aceitaram que os alunos poderiam fraudar e optaram por elaborar questões que demandassem níveis cognitivos mais elevados para chegar à sua resolução, como interpretar e analisar situações.

Longhurst et al. (2020) apontam que os AVA possuem mecanismos que dificultam a fraude como a ordenação aleatória de questões, o impedimento do aluno em retornar a uma questão já respondida, o controle do tempo e o registro das teclas que foram pressionadas durante a avaliação. Contudo, Pather et al. (2020) enfatizam que limitar o tempo de avaliação é um fator complicador, visto que a avaliação necessita de ajustes quando se leva em consideração alunos com dificuldades de aprendizagem e aqueles que requerem um maior tempo para finalizar a prova.

Segundo Palloff e Pratt (2015a), a maioria dos AVA possuem a função de teste e Quiz e os professores acabam por utilizá-los nas avaliações, apesar de não serem as estratégias mais adequadas. Conforme os autores, com frequência, as provas on-line não são projetadas para medir o nível de domínio do conteúdo, o que torna esse conjunto de estratégias susceptíveis à fraude. Palloff e Pratt (2009) ressaltam, ainda, que a cola e o plágio acontecem tanto no ambiente presencial quanto on-line e que a aplicação de uma quantidade variada de pequenas avaliações dentro das atividades diminui a chance de acontecer uma fraude.

Por fim, para Palloff e Pratt (2009) é importante que a avaliação on-line seja centrada no aluno e que o leve à reflexão. Ela precisa ser de fácil compreensão, construída para ser executada no ambiente on-line, alinhada aos objetivos de aprendizagem e o professor deve prover feedback imediato. As avaliações devem ser colaborativas e públicas para que os alunos consigam ver o que os seus colegas estão fazendo e pratiquem a emissão de feedback. É necessário que haja rubricas claras, ou seja, que haja critérios sobre o que fazer em cada situação e como cada critério será pontuado. Não obstante, os alunos devem contribuir com a avaliação, através da sua visão sobre como ela poderia ser elaborada e conduzida. 
Figura 2 - Síntese das ferramentas tecnológicas e estratégias pedagógicas utilizadas por professores de anatomia para o ensino remoto durante a pandemia do coronavírus. Abreviações: AVA - ambiente virtual de aprendizagem; MA - metodologias ativas de ensino-aprendizagem

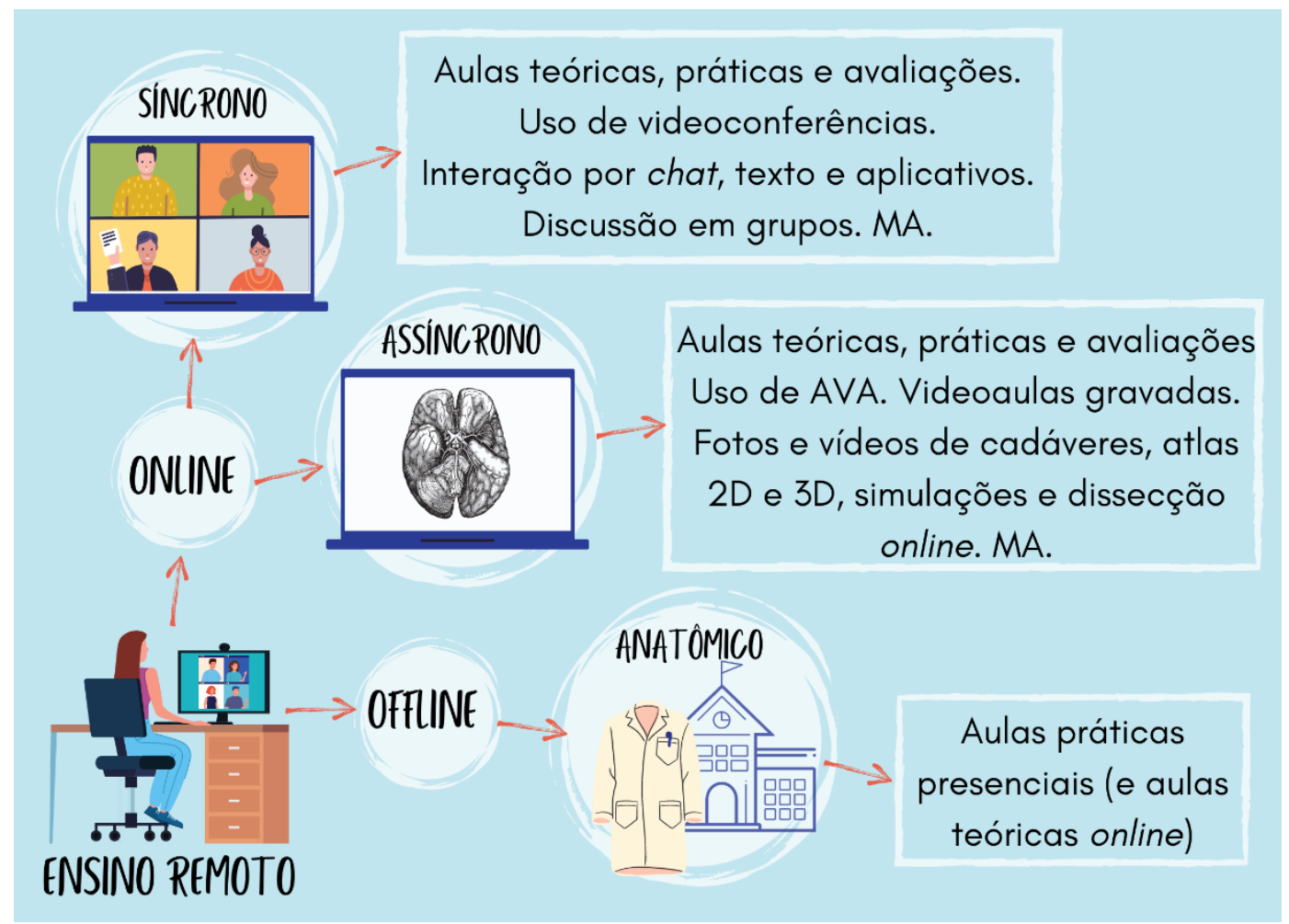

Fonte: Elaborado pela autora (2021).

\subsection{Percepções sobre o ensino remoto}

A percepção dos professores de anatomia sobre o ensino remoto convergiu entre os estudos, apesar de serem conduzidos em países com diferentes realidades socioculturais e econômicas. Os resultados em comum incluem a oportunidade de criar RE, melhorar as habilidades pessoais no uso de TDIC, dificuldade em avaliar on-line e na relação professor-aluno, falta de tempo e sobrecarga de trabalho. Essa análise não foi possível no estudo de Harmon et al. (2021) diante da ausência de elementos claros que evidenciassem as percepções dos professores sobre o ensino remoto (Figura 3).

O estudo de Cheng et al. (2020) apontou a diversidade de métodos de ensino, o desenvolvimento de RE e o desenvolvimento de novos métodos de ensino como os três maiores benefícios do ensino remoto. Como dificuldades, os professores apontaram a avaliação do progresso dos alunos, a instabilidade do AVA, a escassez de RE, a falta de preparo para o ensino on-line e a elaboração de avaliações somativas.

No estudo de Longhurst et al. (2020), a análise FOFA (força, oportunidades, fraquezas e ameaças) mostrou como forças o desenvolvimento de novos RE e a melhora das habilidades no uso de TDIC. Entre as fraquezas, foi apontado o pouco tempo para aprender a usar as tecnologias digitais e para criar materiais de boa qualidade, a ausência de aulas práticas com cadáveres e a avaliação on-line. Entre as ameaças, identificou-se o baixo engajamento discente e a relação professor-aluno. Como oportunidades, a colaboração acadêmica, o trabalho remoto de casa e a possibilidade de incorporar futuramente o ensino híbrido no currículo de anatomia foram destacados. 
Pather et al. (2020) apontaram que os professores tiveram grande facilidade na transposição das aulas teóricas para o ambiente on-line e uma rápida aquisição de habilidades em pedagogia on-line e produção de mídias digitais. Entre os desafios e dificuldades, foi citado o acesso a softwares e o suporte à educação on-line, dificuldades técnicas e de conexão, assim como a transposição da aula prática e das avaliações para o ambiente on-line. Muitos professores relataram o aumento da carga de trabalho e a extensão do tempo dedicado ao trabalho, que incluiu finais de semana. Alguns professores optaram por usar vídeos disponíveis on-line nas aulas práticas, contudo, a curadoria de vídeos no YouTube consumiu muito tempo.

Em seu estudo, Wolniczak et al. (2020) identificaram como aspectos positivos a produção de RE com mais detalhamento e representação das estruturas anatômicas, o uso de diferentes métodos de preparo de RE e a possibilidade de ter um treinamento adicional. Como pontos negativos, o ensino on-line demandou um tempo três vezes maior e a comunicação com os alunos foi difícil. Eles consideraram, ainda, difícil controlar a disseminação dos RE disponibilizados no AVA para fora desse ambiente. Este último item é preocupante, porque os professores relataram criar os seus RE fotografando ou filmando cadáveres e peças anatômicas das suas instituições. Uma vez que estes materiais são, na verdade, pessoas que doaram o seu corpo ao estudo da anatomia, sua dignidade deve ser preservada. Longhurst et al. (2020) comentam que a Autoridade de Tecidos Humanos (Human Tissue Authority HTA), da Inglaterra, alertou sobre a necessidade de avaliar se o doador consentiu que o seu corpo fosse fotografado ou filmado antes do seu uso nas aulas remotas de anatomia. Nota-se que este novo formato de ensino traz consigo a necessidade em se discutir a legislação acerca dos termos assinados na doação de corpos para o estudo da anatomia.

Pather et al. (2020) referem um aumento da correspondência entre professores e alunos. Eles dizem que este fenômeno está relacionado à percepção pelo aluno de que o professor está sempre disponível e que, por outro lado, o professor se sente pressionado a passar mais tempo interagindo com eles. No estudo de Cheng et al. (2020), alguns professores alertaram que a maior interação com os alunos foi essencial para um ensino on-line de sucesso, uma vez que, segundo eles, isto pode reduzir o distanciamento psicológico percebido e o estresse, fazendo com que os alunos se sentissem acolhidos na sua aprendizagem on-line.

Pather et al. (2020) discutiram a comunicação on-line, pois a inteligibilidade da mensagem por vezes se torna não clara ou conflituosa e que, no contexto da pandemia, em que os alunos estão ansiosos e estressados, é importante uma comunicação positiva para prover suporte e diálogo aberto. No referido estudo, alguns professores entrevistados indicaram a importância de deixar claro para o aluno quais são as expectativas do professor sobre o seu progresso diário ou semanal, os critérios de avaliação e o provimento de avaliação formativa.

Palloff e Pratt (2015a) nos dizem que para obter uma participação máxima dos alunos, o professor precisa se mostrar presente no ambiente on-line, ao entrar frequentemente no AVA e contribuir com as discussões, mas sem liderar, caso contrário, a sua participação excessiva reduzirá a interação entre os alunos, aumentando a dependência da figura do professor. Os alunos também devem ser ensinados sobre como estudar on-line e a gerenciar o seu tempo de estudo. Em geral, os professores acreditam que, ao entrar neste ambiente, os alunos já sabem o que fazer, mas isso nem sempre é verdade. Ao detectar uma participação reduzida, o professor deve auxiliar o aluno a estabelecer boas práticas de estudo on-line para que este alcance um bom desempenho. Ainda, o professor deve criar uma atmosfera acolhedora que promova o senso de comunidade e que motive o aluno a estar presente. 


\subsection{Perspectivas sobre a educação em anatomia pós-pandemia}

A experiência do ensino remoto provocou a reflexão dos professores sobre o futuro da educação em anatomia no período pós-pandemia (Figura 3). Foi observada uma abertura à inserção de TDIC no currículo e a continuar ensinando os conteúdos teóricos virtualmente, seja totalmente ou parcialmente, através do ensino híbrido. Com relação às aulas práticas, existiu uma grande divergência de opiniões sobre a continuidade no uso de cadáveres, assim como a sua substituição por RE digitais. A criação de comunidades de práticas docentes para o compartilhamento de RE e experiências também foi citado, bem como um maior apoio institucional para a educação on-line e para o enfrentamento de futuras crises.

No estudo de Cheng et al. (2020), 36\% dos professores estavam dispostos a continuar ministrando todo o conteúdo teórico por meio de aulas on-line e $0,6 \%$ professores estariam dispostos a lecionar todo o conteúdo prático on-line. Alguns professores se mostraram positivos com o ensino on-line (24\%), enquanto outros enfatizaram ser indispensáveis as aulas práticas (25\%). Wolniczak et al. (2020) concluíram que, após a experiência do ensino remoto, eles (professores) poderiam ser designados a ensinar on-line ou de forma híbrida no próximo semestre e complementaram sinalizando que os vídeos e fotos produzidos por eles poderão ser utilizados de forma permanente como RE digitais pós-pandemia (WOLNICZAK, 2020). Longhurst et al. (2020) também identificaram a possibilidade da incorporação do ensino híbrido no currículo. Eles ressaltaram que a aquisição de novas habilidades no uso de TDIC pelos professores possui o potencial de transformar a educação médica pela incorporação do ensino on-line em todos os aspectos do currículo.

Pather et al. (2020) relatam que quase todos os respondentes do seu estudo consideram que a pandemia trará mudanças permanentes na educação em anatomia devido à grande dimensão das mudanças implementadas. Alguns professores revelaram ainda que estas mudanças trarão à discussão as abordagens que têm como base as atividades laboratoriais (anatômico) em favor de abordagens on-line e remotas. Ainda, que a pandemia promoverá a revisão do currículo e o desenvolvimento estratégico de $\mathrm{RE}$ que perdurem no período pós-pandemia, especialmente se eles conseguirem melhorar o acesso e a equidade na educação.

Alguns estudos revelaram que houve a suspensão dos programas de doação de cadáveres para as universidades devido ao risco de contaminação de alunos e professores pelo novo coronavírus. Cheng et al. (2020) discutiram que, a curto prazo, pode haver uma escassez de corpos e, com isso, ainda haverá uma dependência dos RE digitais para prover aulas práticas pós-pandemia. Singal, Bansal e Chaudhary (2020) dizem que, há anos, os anatomistas vêm resistindo a promover mudanças na sua prática pedagógica e que o cenário atual da pandemia promoverá uma transição histórica, em que muitos paradigmas serão mudados. Eles dizem também que já foi previsto que a anatomia será ensinada sem cadáveres na próxima década.

Quanto às instituições, Cheng et al. (2020) alertam que será necessário que as universidades melhorem os seus AVA e estabeleçam um plano de contingência completamente on-line para lidar com incidentes inesperados, como a pandemia do novo coronavírus. Pather et al. (2020) também alegam sobre a necessidade de desenvolver um plano de contingência pelos gestores e a capacitação do corpo docente, porque outras situações que demandem o ensino on-line podem surgir no futuro. 
Comunidades de práticas externas à instituição de origem surgiram durante a pandemia e, além de compartilharem experiências e habilidades, também compartilharam RE (PATHER et al., 2020). Seguindo essa mesma direção, Longhurst et al. (2020) apontaram como futuro da educação em anatomia uma maior colaboração e troca entre professores de diferentes instituições no mesmo país e com outros países. Eles ressaltam que a expertise adquirida na realização de videoconferências pode apoiar instituições cujo corpo docente de anatomia é pequeno, nos quais eles podem se conectar a grupos de professores de outras instituições, assim como promover reuniões para a troca de experiências entre subespecialidades da anatomia.

Crato (2020) prevê, como consequência da experiência digital vivida, que haja um contato ampliado entre professores e alunos, para além da sala de aula, mediado pelas TDIC. De acordo com ele, será possível solicitar mais autonomia no estudo, maior cooperação entre os alunos e a escolha do uso de meios presenciais e digitais passará a ser feita com maior liberdade e melhor critério, sendo que, para certos propósitos, um meio pode ser melhor do que o outro. Crato (2020) também pondera que as TDIC devem estar em consonância com os objetivos curriculares e que a escolha de uma determinada forma de ensino deve ser definida pela sua eficácia, pelo conteúdo que se pretende abordar e pela capacidade que se pretende desenvolver.

Palloff e Pratt (2015b) ressaltam que os professores que já ensinaram on-line têm maior consideração por essa modalidade do que os que nunca fizeram. Isso justifica a grande abertura pós-pandemia ao ensino de anatomia de forma híbrida ou exclusivamente on-line, pelo menos para as aulas teóricas. Eles também salientam que se deve focar na interatividade e não no conteúdo, construindo uma comunidade de aprendizagem entre os alunos. Os papéis devem mudar, os professores precisam abdicar até certo ponto do controle e permitir que os alunos assumam a liderança das atividades de aprendizagem. Tanto docentes quanto alunos precisam de capacitação sobre como ensinar e aprender no ambiente on-line, contudo, a urgência na implementação do ensino remoto dificultou as ações de capacitação. Palloff e Pratt (2015b) também apontam que os docentes devem ter apoio institucional e as instituições devem desenvolver um plano estratégico, infraestrutura e tecnologia, o que também foi percebido no relato dos professores dos estudos analisados. 
Figura 3 - Percepções sobre o ensino remoto e o que pensam os professores sobre o futuro da educação em anatomia pós-pandemia. Abreviação: TDIC - tecnologias digitais de informação e comunicação

\section{ENSINO REMOTO}

\section{Aspectos positivos}

- Criação de recursos educacionais

- Diversidade de métodos de ensino

- Novas habilidades no uso de TDIC

$$
\begin{aligned}
& \text { Desafios } \\
& \text { - Avaliação online } \\
& \text { - Relação professor-aluno } \\
& \text { - Tempo } \\
& \text { - Sobrecarga de trabalho }
\end{aligned}
$$

\section{PÓS-PANDEMIA}

\section{Perspectivas}

- Abertura ao uso de TDIC

- Ensino híbrido

- Reavaliar a uso de cadáveres em aulas práticas

- Mudanças curriculares

- Comunidade de práticas docentes

- Apoio institucional
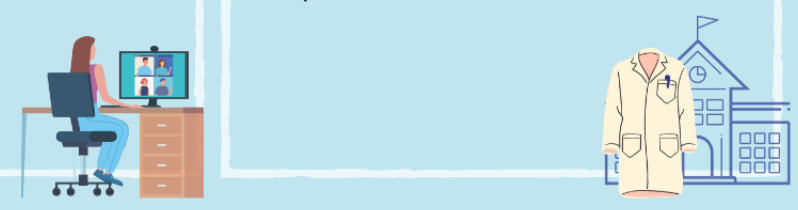

Fonte: Elaborado pela autora (2021).

\section{Considerações finais}

Para analisar as ferramentas tecnológicas e as estratégias pedagógicas utilizadas durante o ensino remoto da anatomia humana, optou-se por realizar uma análise e síntese das experiências dos professores dos estudos selecionados, uma vez que uma única solução pode não servir a todos os contextos. O cenário atual de elevado número de novos casos e de mortes por COVID-19 no Brasil e a demora na imunização a nível nacional sinalizam que o ensino remoto (ou híbrido) ainda se manterá vigente ao longo do ano de 2021, pelo menos no Brasil. O conhecimento das soluções encontradas em outros países e as percepções docentes, combinadas às vivências pessoais do leitor, podem ajudar a nortear a continuação do ensino remoto, assim como provocar uma reflexão sobre o futuro da educação em anatomia.

Nos estudos analisados, as mudanças foram feitas de forma corrida, sem tempo para reflexão e demandaram um tempo muito maior do que o habitual para o preparo de aulas teóricas, práticas e avaliações, especialmente pela demanda em criar novos materiais. Os professores utilizaram um grande repertório de TDIC, contudo, a presente revisão não teve como objetivo descrever cada aplicativo ou website utilizado, mas sim expor de forma mais ampla as soluções encontradas em um período de tempo tão curto. Caso haja interesse, a lista de recursos utilizados pode ser consultada em detalhes em cada estudo. Em geral, a percepção dos professores sobre o ensino remoto demonstrou: oportunidade de criar RE e de melhorar as suas habilidades no uso de TDIC, dificuldade em avaliar on-line e em manter a relação professor-aluno, a falta de tempo e a sobrecarga de trabalho.

Um aspecto importante identificado foi a transposição das aulas presenciais para o ambiente on-line por meio da adaptação de recursos sem contextualização pedagógica, justificada pela urgência que o momento demandava, que foi o início da pandemia do novo 
coronavírus no primeiro semestre de 2020. Entretanto, diante o cenário atual de agravamento da pandemia, cabe, neste momento, uma reflexão sobre os estudos relatados, sobre as experiências pessoais vividas até aqui, assim como a troca de conhecimentos com os pares através de comunidades de práticas em busca de melhores práticas pedagógicas alinhadas aos objetivos educacionais e ao currículo do curso. Conforme já apontado pelos estudos, também é importante que a instituição de ensino se faça presente, auxiliando os docentes e alunos com relação à infraestrutura necessária ao ensino remoto, incluindo a capacitação docente para o ensino on-line para além do instrumento, com um olhar mais pedagógico e mediador das TDIC.

É difícil prever em médio e longo prazo o impacto da experiência do ensino remoto sobre a educação em anatomia, mas os estudos analisados apontam algumas direções. Elas incluem uma maior abertura dos professores à inserção de TDIC e ao ensino híbrido, on-line e remoto, a reavaliação da necessidade de aulas práticas com cadáveres e a reavaliação do currículo de anatomia. Ainda incluem a colaboração docente através de comunidades de práticas e um maior suporte institucional. Infelizmente, a presente revisão não encontrou estudos relatando o ensino remoto de anatomia no território brasileiro nas bases pesquisadas, sendo um campo ainda aberto para investigação. Por fim, somente o tempo dirá se o aprendizado adquirido pelos professores durante a pandemia será incorporado à educação em anatomia pós-pandemia ou perdido com o tempo.

\section{Referências}

ARRUDA, Eucidio Pimenta. Educação Remota Emergencial: elementos para políticas públicas na educação brasileira em tempos de Covid-19. EmRede - Revista de Educação a Distância, v. 7, n. 1, p. 257-275, maio. 2020. Disponível em:

https://www.aunirede.org.br/revista/index.php/emrede/article/view/621. Acesso em: 13 jan. 2021.

BOFF, Tália Cássia et al. O uso da tecnologia no ensino da anatomia humana: revisão sistemática da literatura de 2017 a 2020 . Medicina (Ribeirão Preto), v. 53, n. 4, p. 447-455. 2020. DOI: 10.11606/issn.2176-7262.v53i4p447-455. Disponível em:

https://www.revistas.usp.br/rmrp/article/view/169288. Acesso em: 13 jan. 2021.

CHENG, Xin et al. Gross Anatomy Education in China during the Covid-19 Pandemic: A National Survey. Anatomical Sciences Education. 2020. Advance online publication. DOI: 10.1002/ase.2036. Disponível em:

https://anatomypubs.onlinelibrary.wiley.com/doi/10.1002/ase.2036. Acesso em: 13 jan. 2021.

CRATO, Nuno. La grande illusion. Saber \& Educar, n. 28. 2020. DOI:

10.17346/se.vol28.390. Disponível em:

http://revista.esepf.pt/index.php/sabereducar/article/view/390. Acesso em: 13 jan. 2021.

EVANS, Darrel et al. Going Virtual to Support Anatomy Education: A STOPGAP in the Midst of the Covid-19 Pandemic. Anatomical Sciences Education, v. 13, n. 3, p. 279-283, maio/jun. 2020. Editorial. DOI: 10.1002/ase.1963. Disponível em:

https://anatomypubs.onlinelibrary.wiley.com/doi/abs/10.1002/ase.1963. Acesso em: 13 jan. 2021. 
HARMON, Derek et al. An Analysis of Anatomy Education Before and During Covid-19: May-August 2020. Anatomical Sciences Education. 2021. Advance online publication. DOI: 10.1002/ase.2051. Disponível em:

https://anatomypubs.onlinelibrary.wiley.com/doi/10.1002/ase.2051. Acesso em: 13 jan. 2021.

IWANAGA, Joe et al. A review of anatomy education during and after the COVID-19 pandemic: Revisiting traditional and modern methods to achieve future innovation. Clinical Anatomy, v. 34, n. 1, p. 108-114. 2021. DOI: 10.1002/ca.23655. Disponível em: https://onlinelibrary.wiley.com/doi/full/10.1002/ca.23655. Acesso em: 13 jan. 2021.

LIMA, Luciana de; LOUREIRO, Robson Carlos. Tecnodocência: Integração entre tecnologias digitais da informação e comunicação e docência na formação do professor. 1. ed. Fortaleza: Edições UFC, 2019. E-book. 121 p.

LONGHURST, Georga et al. Strength, Weakness, Opportunity, Threat (SWOT) Analysis of the Adaptations to Anatomical Education in the United Kingdom and Republic of Ireland in Response to the Covid-19 Pandemic. Anatomical Sciences Education, v. 13, n. 3, p. 301-311. 2020. DOI: 10.1002/ase.1967. Disponível em: https://anatomypubs.onlinelibrary.wiley.com/doi/full/10.1002/ase.1967. Acesso em: 13 jan. 2021.

MARTINS, Ronei Ximenes. A COVID-19 e o fim da educação a distância: um ensaio. EmRede - Revista de Educação a Distância, v. 7, n. 1, p. 242-256, maio. 2020. Disponível em: https://www.aunirede.org.br/revista/index.php/emrede/article/view/620. Acesso em: 13 jan. 2021.

MCMENAMIN, Paul et al. Do we really need cadavers anymore to learn anatomy in undergraduate medicine?. Medical Teacher, v. 40, n. 10, p. 1020-1029. 2018. DOI: 10.1080/0142159X.2018.1485884. Disponível em: https://www.tandfonline.com/doi/abs/10.1080/0142159X.2018.1485884?journalCode=imte2. Acesso em: 13 jan. 2021.

MOHER, David et al. Preferred reporting items for systematic reviews and meta-analyses: the PRISMA statement. PLoS Medicine, v. 6, n. 7, e1000097, jul. 2009. DOI: 10.1371/journal.pmed.1000097. Disponível em: https://journals.plos.org/plosmedicine/article?id=10.1371/journal.pmed.1000097. Acesso em: 13 jan. 2021.

MORAN, José Manuel. Os novos espaços de atuação do professor com as tecnologias.

Revista Diálogo Educacional, v. 4, n. 12, p. 1-9, maio/ago. 2004. Disponível em: https://periodicos.pucpr.br/index.php/dialogoeducacional/article/view/6938. Acesso em: 13 jan. 2021.

MOREIRA, José António; SCHLEMMER, Eliane. Por um novo conceito e paradigma de educação digital onlife. Revista UFG, v. 20, n. 26, 2020. DOI: 10.5216/revufg.v20.63438. Disponível em: https://www.revistas.ufg.br/revistaufg/article/view/63438. Acesso em: 13 jan. 2021. 
OMS. Organização Mundial da Saúde. Listings of WHO's response to COVID-19. 29 jun. 2020, atualizado em 28 dez. 2020. Disponível em:

https://www.who.int/news/item/29-06-2020-covidtimeline. Acesso em: 13 jan. 2021.

PALLOFF, Rena; PRATT, Keith. Assessment Online. In: PALLOFF, R. M.; PRATT, K. Assessing the online learner: resources and strategies. California: Jossey-Bass, 2009. E-book. cap. 3.

PALLOFF, Rena; PRATT, Keith. A arte do ensino on-line. In: PALLOFF, R. M.; PRATT, K.Lições da sala de aula virtual: as realidades do ensino on-line. E-book. Tradução: Fernando de Siqueira Rodrigues. 2. ed. Porto Alegre: Penso, 2015a. cap. 2, p. 35-54.

PALLOFF, Rena; PRATT, Keith. Lições aprendidas na sala de aula virtual. In: PALLOFF, R. M.; PRATT, K. Lições da sala de aula virtual: as realidades do ensino on-line. E-book. Tradução: Fernando de Siqueira Rodrigues. 2. ed. Porto Alegre: Penso, 2015b. cap. 9, p. 168-182.

PATHER, Nalini et al. Forced Disruption of Anatomy Education in Australia and New Zealand: An Acute Response to the Covid-19 Pandemic. Anatomical Sciences Education, v. 13, n. 3, p. 284-300. 2020. DOI: 10.1002/ase.1968. Disponível em:

https://anatomypubs.onlinelibrary.wiley.com/doi/full/10.1002/ase.1968. Acesso em: 13 jan. 2021.

PIMENTEL, Mariano; CARVALHO, Felipe da Silva Ponte. Princípios da Educação Online: para sua aula não ficar massiva nem maçante! SBC Horizontes, maio. 2020. ISSN 2175-9235. Disponível em:

http://horizontes.sbc.org.br/index.php/2020/05/23/principios-educacao-online. Acesso em: 13 jan. 2021.

SANTOS, Gilberto Lacerda dos. Ensinar e aprender no meio virtual: rompendo paradigmas.

Educação e Pesquisa, v. 37, n. 2, p. 307-320, maio/ago. 2011. DOI:

10.1590/S1517-97022011000200007. Disponível em:

https://www.scielo.br/scielo.php?script=sci_arttext\&pid=S1517-97022011000200007. Acesso em: 13 jan. 2021.

SAVERINO, Daniele. Teaching anatomy at the time of COVID-19. Clinical Anatomy. 2020. Advance online publication. DOI: 10.1002/ca.23616. Disponível em: https://onlinelibrary.wiley.com/doi/full/10.1002/ca.23616. Acesso em: 13 jan. 2021.

SILVA, Ketia Kellen Araújo da; BEHAR, Patricia Alejandra. Competências digitais na educação: uma discussão acerca do conceito. Educação em Revista, v. 35, e209940. 2019. DOI: 10.1590/0102-4698209940. Disponível em: https://www.scielo.br/scielo.php?script=sci_arttext\&pid=S0102-46982019000100419. Acesso em: 13 jan. 2021.

SINGAL, Anjali; BANSAL, Agam; CHAUDHARY, Pankaj. Cadaverless anatomy: Darkness in the times of pandemic Covid-19. Morphologie: Bulletin de L'Association des Anatomistes, v. 104, n. 346, p. 147-150, set. 2020. DOI: 10.1016/j.morpho.2020.05.003. Disponível em: https://europepmc.org/article/med/32518047. Acesso em: 13 jan. 2021. 
SINGH, Keerti et al. Teaching anatomy and dissection in an era of social distancing and remote learning. Advances in Human Biology, v. 10, n. 3, p. 90-94. 2020. DOI:

10.4103/AIHB.AIHB_87_20. Disponível em:

https://www.aihbonline.com/article.asp?issn=2321-8568; year=2020; volume=10;issue $=3$; spag e=90; epage=94; aulast=Singh. Acesso em: 13 jan. 2021 .

TALAMONI, Ana Carolina Biscalquini; BERTOLLI FILHO, Claudio. A anatomia e o ensino de anatomia no Brasil: a escola boveriana. História, Ciências, Saúde-Manguinhos, Rio de Janeiro, v. 21, n. 4, p. 1301-1322, dez. 2014. DOI: 10.1590/S0104-597020140. Disponível em http://www.scielo.br/scielo.php?script=sci_arttext\&pid=S0104-59702014000401301\&lng=en \&nrm=iso. Acesso em 13 Jan. 2021.

NICOLESCU, Basarab. Um novo tipo de conhecimento - transdisciplinaridade. In:

UNESCO. Educação e transdisciplinaridade. E-book. Brasília: UNESCO, 2000. cap. 1, p. 9-25. Disponível em: https://unesdoc.unesco.org/ark:/48223/pf0000127511. Acesso em 12 Mai 2021.

WOLNICZAK, Erik et al. Course of macroscopic anatomy in Magdeburg under pandemic conditions. GMS Journal for Medical Education, v. 37, n. 7, p. Doc65, dez. 2020. DOI: 10.3205/zma001358. Disponível em:

https://www.ncbi.nlm.nih.gov/pmc/articles/PMC7740037/. Acesso em: 13 jan. 2021.

Recebido em janeiro de 2021.

Aprovado em maio de 2021. 